\title{
Condições de vida e saúde do trabal hador em assentamento rural
}

\author{
Life and health conditions of a worker in a rural settling
}

RosemeireA parecida Scopinho ${ }^{1}$

1 Universidade Federal de São Carlos. Rodovia Washington Luiz Km 235, M onjolinho. 13656-905 São Carlos SP. scopinho@ufscar.br
Abstract The wide spread of cooperated and selfmanaged ways of work, not only in the urban but also in rural areas, makes relevant the debate on the contributive potential of these experiences for the solution of social problems. This articletries to reflect on the way this organizational logic is able to improvelifeand health conditions of rural workers. Studying the organizational process of a rural settling, I have tried to understand the meaning given to health-illness by these workers and the health practices being developed. Considering the objective and subjective aspects involved in the concept of life condition and starting from a perspective which deals with the process of knowledge production as social construction, I analyzed and compared information obtained from documentary analysis, interviews and observation of the daily routine of life and work in the settling. The contrast between urban and rural life way is a strong feature in the meaning of health-illness. Between idealized concepts and feasible practices, the attempt to solve problems and make health a social right, came up against the fragmentary and inarticulate way that public policy involved in theland reform has been implemented by the state. Key words Life and health condition, Work and cooperation, Rural settling, Social movements and health
Resumo A proliferação das formas de trabalho cooperado e autogestionário, na cidade e no campo, torna relevante 0 debate sobre o potencial de contribuição das experiências na solução de problemassociais. 0 artigo procura refletir sobre como esta lógica organizativa pode melhorar as condições de vida e a saúde dos trabalhadores rurais. Estudando o processo organizativo de um assentamento rural, procurei compreender os sentidos atribuídos pel ostrabalhadoresà saúde doença eas práticas de saúde desenvolvidas. Considerando aspectos objetivos e subjetivos envolvidos na noção de condição de vida e a partir de uma perspectiva teórico-metodológica que trata o processo de produção do conhecimento como construção social, analisei e confrontei informações obtidas através de análise documental, entrevistas e observações do cotidiano de trabalho e vida no assentamento. A contraposição do modo de vida rural com o urbano é traço marcante do sentido da saúde-doença. Entre sentidos idealizados e práticas possíveis, as tentativas para solucionar os problemas e concretizar a saúde como direito social esbarravam no modo fragmentado e desarticulado com que as políticas públicas envolvidas na reforma agrária têm sido implementadas pelo Estado.

Palavras-chave Condição de vida e saúde, Trabalho e cooperação, Assentamento rural, M ovimentos sociais e saúde 
Introdução

No Brasil rural, as condições de trabalho e de vida sempre foram muito precárias e, quanto mais o nosso ol har focaliza a modernidade, mais enxerga 0 arcaico. Especialmente a monocultura intensiva e extensiva praticada no mundo do agronegócio tem sido fonte indiscutível de desgaste e adoecimento ${ }^{1}$. Por exemplo, o definhamento progressivo da saúde tem levado, recentemente, os trabalhadores canavieiros da região de Ribeirão Preto - considerada uma das regiões agrícolas mais "modernas" eimportantes do país - à morte por exaustão $0^{2,3}$.

N esta região, a reestruturação produtiva agroindustrial, ao gerar a precarização do trabalho e o desemprego estrutural na cidade e no campo, também tem gerado descontinuidades e rupturas na ordem social. Os assentamentos rurais têm sido considerados como uma expressão da luta social dos trabalhadores do campo pela melhoria das condições de trabal ho e vida, espaços de múltiplas relações sociais e trocas de saberes $^{4}$, que podem contribuir para solucionar 0 problema do desemprego e da miséria que os afetam. Nos assentamentos organizados pelo M ovimento dos Trabalhadores Rurais Sem Terra (M ST), a cooperação - entendida como ação social, organizada ou espontânea, articulada por objetivos comuns para solucionar problemas concretos - tem sido utilizada como princípio fundamental no processo organizativo, não apenas no âmbito da organização e gestão do processo produtivo, mastambém nas outras dimensões da vida cotidiana ${ }^{5}$, entre elas os cuidados com a saúde.

A relação trabalho-condição de vida e saúde vem sendo investigada, predominantemente, no mundo urbano, no âmbito do trabalho organizado sob o princípio da heterogestão. A recente proliferação das formas de trabal ho cooperado e autogestionário, na cidade e no campo, torna relevante a reflexão sobre o potencial de contribuição das experiências na solução dos problemas sociais. Este artigo tem por objetivo refletir sobre como essa outra lógica organizativa pode contribuir para melhorar as condições de vida ea saúde dos trabal hadores rurais assentados. Estudando o processo organizativo de um assentamento localizado no coração da região canavieira de Ribeirão Preto (SP), procurei compreender os sentidos atribuídos pelos trabal hadores à saúde-doença e as práticas de saúde desenvolvidas.

Entendendo que condições de vida refere-seà reprodução social no sentido objetivo, como pos- sibilidade de acesso, através do trabalho, aos bens de consumo coletivo, esubjetivo, como possibilidade de controle das relações sociais e políticas no trabalho ${ }^{6}$, neste caso ao poder de decisão e autogestão, recorri à noção de modo de vida para entender como as condições objetivas são vivenciadas pelos trabalhadores, por que ela remete aos valores, tradições e códigos morais presentes nos seusuniversossimbólicos ${ }^{7}$. Ostrabalhadores constroem e partilham sentidos sobrea realidade vivida com a finalidade não apenas de interpretá-la, mas também detransformá-la, sentidos esses que expressam suas identidades sociais e culturais e não são abstrações puras, por que tanto são gerados quanto se integram às suas experiências e práticas cotidianas, refletindo e constituindo reflexos da estrutura social, da ideologia e da cultura que as sustentam.

Entre as várias dimensões da vida humana contempladas nesta noção de condições de vida, destaquei o cuidado com a saúde sem, no entanto, desconsiderar os processos econômicos e políticos que configuram a atual questão social brasileira, que ora limitam, ora potencializam 0 processo organizativo dos trabalhadores rurais, fazendo da reforma agrária uma estratégia de luta pela mel horia das condições de trabal ho ede vida. A partir de uma perspectiva metodológica que trata o processo de produção do conhecimento como construção social possibilitada pelo diálogo travado entre sujeitos portadores de saberes distintos ${ }^{8}$, analisei informaçõesobtidas através de análise bibliográfica e documental, de entrevistas semiestruturadas individuais e coletivas realizadas com os trabalhadores e de observações do cotidiano de trabal ho e vida no assentamento, confrontando-as de modo a identificar consensos e dissensos nos conteúdos. A reflexão está organizada de modo que, primeiramente, discuto como a saúde tem sido tratada no ideário organizativo do MST para depois analisar como este ideário concretiza-se em sentidos e práticas no universo investigado.

Trabalho, cooperação e saúde no ideário do MST

A construção de diretrizes organizativas das ações de saúde no M ST iniciou-se com a realização de um diagnóstico para identificar a situação de saúde em assentamentos e acampamentos de reforma agrária situados em 23 estados brasileiros, no ano de 1999. A falta de acesso à rede de abastecimento deágua eesgoto eaos serviços de cole- 
ta de lixo contribuía para a proliferação dedoenças infecciosas e parasitárias. Prevaleciam as doenças respiratórias (especialmente, entre as crianças e os idosos), dermatológicas, infecto-parasitárias, cardiovasculares e osteomusculares. Os coeficientes de mortalidade, geral einfantil, e os índices de morbidade eram superiores à mé dia nacional enão existiam programas eações de planejamento familiar, saúde da mulher e doenças sexualmente transmissíveis. A precariedade das condições de trabal ho evida no meio rural, a inexistência ea dificuldade deacesso aos serviços de saúde e à assistência especializada, as barreiras culturais e a falta de informação contribuíam para agravar ainda mais a situação e, ao mesmo tempo, constituíam os mais importantes desafios a serem superados na luta pela defesa da saúde do trabalhador rural brasileiro ${ }^{9}$. Os poucos estudos existentes confirmam a precariedade da saúde nos acampamentos e assentamentos de reforma agrária brasileiros ${ }^{10-14}$.

Se não há dúvida quanto ao tamanho e à gravidade do problema, que significados atribui o M ST à saúde e que tipo de propostas são pensadas para enfrentar esta realidade? U ma sociedade com saúde é onde os homens e mulheres vivem com liberdade para participar eter seus direitos respeitados. Onde a renda e a riqueza sejam distribuídas com igualdade. [...] M as para queisso se torne realidade, é necessário a organização de todos os trabalhadores e trabalhadoras para lutar por uma sociedade justa e saudável ${ }^{15}$.

A saúde deveria ser o resultado de políticas econômicas e sociais voltadas para a equidade, que tanto possam garantir o acesso dos trabaIhadores aos meios de produção, aos direitos sociais eaos bens de consumo coletivos quanto cultivar valores de justiça, equidade e organização política. Considerando as várias dimensões da vida humana implícitas nesta idéia de saúde, o MST propõe práticas calcadas na promoção ena prevenção e no fortalecimento da capacidade de organização e luta popular. A luta pela reforma agrária deve conter a luta pela saúde, que não depende apenas da oferta de serviços médicos e remédios. A solidariedade, o respeito à sabedoria popular e à natureza também são valores básicos para alcançar este ideal ${ }^{15}$. Aspecto importante a ser destacado na forma de entender a saúde éa sua relação direta com o meio ambiente. Um ambiente saudável depende diretamente da relação que o homem estabelece com a natureza através do trabalho, que na agricultura envolve a preservação da vida nos rios, nas matase no ar. Por isto, a proposta é produzir com base na agroecologia, que dispensa o uso de agrotóxico e insumos químicos poluentes, as queimadas e os desmatamentos que provocam a erosão e 0 enfraquecimento dos solos e mudanças climáticas. Especialmente, procura-se impedir o uso de sementes transgênicas, dado que se defende que os efeitos deste tipo de alimentos para a saúde aindanão estão suficientementeesclarecidos eque a preservação e recuperação das sementes crioulas é uma questão de soberania e de segurança alimentar ${ }^{16}$.

Conhecer, mobilizar e organizar são as palavras de ordem, quando se trata de fazer valer 0 direito à saúde. Conhecer tanto os direitos inscritos na lei como os problemas de saúde, mobilizar e organizar a população para participar e se fazer representar nas instâncias que definem a política de saúde, através das conferências econsel hos municipais ${ }^{17}$. N os assentamentos e acampamentos, a estratégia utilizada para promover a saúdeéa organização de coletivos de saúdeque procuram implementar ações de saneamento ambiental, resgatar o conhecimento popular sobre o uso de plantas medicinais através da organização de hortas e da manipulação artesanal de medicamentos, além de incentivar as discussões sobre proteção ambiental e soberania alimentar, relações familiares (especialmente, o cuidado com a infância e a juventude) e a participação nos Consel hos Municipais de Saúde $e^{15}$.

O MST entende que não se deve assumir as responsabilidades do Estado porque, se "a saúde é direito de todos e dever do Estado", cabe aos movimentos sociais mobilizar eorganizar os trabalhadores para reivindicar os seus direitos. No entanto, dadas as carências da população oriunda dos acampamentos e a situação objetiva de cada assentamento, em termos de acesso aos serviços básicos, a assistência à saúde do assentado égarantida, minimamente, através de estratégias diversas, desde 0 investimento na formação, a participação nos consel hos municipais e o estabelecimento de parcerias com os poderes locais, especialmente no âmbito do Programa de Saúde da Família (PSF), até o incentivo ao voluntariado para resolver problemas emergenciais (transporte de pacientes, por exemplo).

A partir do ano 2000, o Coletivo Nacional de Saúde passou a elaborar, anualmente, pautas específicas para orientar a negociação com o M inistério da Saúde. 0 diálogo estabelecido com 0 Estado foi institucionalizado através do Grupo da Terra (Portaria M S n ${ }^{\circ}$ 2460/GM , de 12/12/05), resultando em parcerias (com a Fundação $\mathrm{Naci-}$ onal de Saúde e a Fundação O swaldo Cruz, por 
exemplo) e programas (DST/Aids, Saúde da Mulher, Farmácia Verde) que priorizam a educação popular. O M ST consideraquehouveavanços na direção do fortalecimento do SUS, especialmente no que se refere aos princípios de equidade, intersetorialidade e integralidade. As de mandas por financiamento priorizam desenvolver ações educativas e solucionar a crônica falta de acesso aos serviços, através da revisão dos valores do Piso de Atenção Básica (PAB) e da criação de um PAB rural, como forma de estruturar as ações de saúde nos assentamentos para lidar com as vel has e as novas demandas. A intersetorialidade ganhou contorno na medida em que saneamento básico, infraestrutura, preservação ambiental, geração de renda, entre outros, são itens essenciais de reivindicação. Somam-se a essas reivindicações os esforços para fortalecer o PSF rural e para conferir reconhecimento aos diplomas dos militantes formados em medicina comunitária pela Escola Latino-americana (Elan), localizada em H avana, através de convê nio estabelecido entre o MST e o governo cubano, para que eles possam atuar como profissionais de saúde nos assentamentos brasileiros.

O campo, a cidade e os sentidos da saúde-doença

No assentamento investigado, um dos traços mais marcantes do sentido que os trabal hadores rurais atribuem à saúde-doença expressa-se, via de regra, na contraposição, direta ou indireta, do modo de vida rural com o urbano, em relação à existência eà qual idade da alimentação edo trabalho eao caráter das relações sociais e interpessoais.

0 Quadro 1 mostra que a vida no assentamento favorecia a saúde porque, por mais precárias que ainda fossem as condições de vida, sempre havia o que comer. M esmo sem os recursos necessários, as famílias produziam alimentos básicos e desenvolviam uma economia detrocas, porque as diretrizes organizativas do M ST preconizavam a diversificação da produção como forma de autosustentação e de modificação de hábitos de consumo tipicamente urbanos. Os trabalhadores destacaram que a qualidade dos alimentos produzida no assentamento é boa porque eles não estão contaminados por agrotóxicos, hormônios e outros produtos químicos que a agroindústria utiliza para aumentar a produtividade e diminuir o tempo de produção. $\mathrm{Nas}$ cidades, além da escassez, que para eles está diretamente relacionada à impossibilidade de consu- mir devido ao alto custo, os alimentos disponíveis não têm boa qualidade por que não se pode confiar nos métodos de produção e nos prazos devalidadedos produtos: Então vocêproduz uma comida sadia, que está sendo feita pela sua própria mão. E na cidade o que você vê? Você vai no mercado, vai comprar uma mandioca, aquela mandioca é pré cozida naquele saquinho, no vácuo, vai saber [há] quanto tempo [ela] está naquele vácuo. 0 frango que você come em um sítio é um frango de quatro meses, cinco meses elá [na cidade] éum frango de trinta e cinco dias. N ão é frango é pintinho e cheio de hormônio.

A saúde também dependia da regularidade nos horários e no número de refeições realizadas diariamente, disciplina que nem sempre o modo de vida urbano permitia cumprir os que viviam nas periferias, desempregados ou com empregos incertos e precários, dependentes de baixos salários: Antes eu era pintor, andava trinta quilômetros todos os dias de bicicleta em rodovias, arriscando a vida. Saía cedo e comia comida fria. Che gava em casa, nem jantava detão cansado queestava, a mulher brigando com a gente, aquela pressão.

Porém, a falta desta disciplina também interferia na saúde dos que moravam no assentamento; por exemplo, aqueles viviam sozinhos, longe do cuidado das famílias ou de um grupo: Quando a gentetinha a horta coletiva, dava comida balanceada. E você vê que a feição [aparência] das pessoas era diferente. $\mathrm{H}$ oje como a pessoa está sozinha e não consegue fazer uma alimentação adequada, no horário e coisa assim, porque está lá na enxada trabalhando eestá semprecom pressa, a gente vê que acaba ficando doente!

0 senhor [nome] que está internado está com anemia, mas porque ele é sozinho, a família não está nem aí com ele. Come muito pouco, a maioria das vezes, o que el e come? Come [cita uma marca de macarrão instantâneo] e doce e por isto teve uma anemia.

Outra importante dimensão da vida que se relacionava à saúde-doença era trabalho. No assentamento, a existência de trabal ho criava a condição essencial para a saúde. 0 trabalho era considerado prazeroso porque lidar com a terra não só garantia o sustento, mas também a liberdade para decidir sobre quando e como trabalhar, podendo evitar o contato com certos tipos de riscos. A saúde melhorou em razão da mudança no modo de trabal har e viver, que envolveu movimentos do corpo, convivência social e despreocupação: 0 próprio emagrecimento da pessoa, porque ela começa a trabalhar e não se preocupar mais, ela tem aquele convívio. Ela começa a ema- 
grecer. 0 senhor [nome] era muito gordo, mal conseguia andar lá na cidade. Hoje, aqui dentro, ele perdeu mais de vinte quilos, anda, trabalha, não é? 0 outro é o senhor [nome] . Quando ele chegou, quando a genteestava com o acampamento ainda na Via Norte, ele tinha muito problema de doença e não conseguia fazer nada, não é? Depois que ele veio para cá, hoje o homem é outro,

Quadro 1. Os sentidos da saúde e da doença, segundo trabal hadores rurais de assentamentos.

\begin{tabular}{|c|c|c|}
\hline & Saúde & Doença \\
\hline Assentamento & $\begin{array}{l}\text { Alimentação sadia, orgânica } \\
\text { Alimentar na hora certa } \\
\text { Três refeições por dia } \\
\text { Digestão mais fácil } \\
\text { Dormir bem, sentir fome } \\
\text { M exer com a terra } \\
\text { Coisa muito gostosa plantar e colher } \\
\text { Trabalho } \\
\text { Longe do químico } \\
\text { Programar o dia (escolher trabalho/ pescaria) } \\
\text { Respeito, companheirismo } \\
\text { Convívio } \\
\text { Mais alegria } \\
\text { Ajuda dos vizinhos } \\
\text { A paz dá saúde } \\
\text { Sossego }\end{array}$ & $\begin{array}{l}\text { Falta alimentação (os sozinhos) } \\
\text { Come qualquer coisa (os sozinhos) } \\
\text { Não tem hora para comer (os } \\
\text { sozinhos) } \\
\text { Poeira } \\
\text { Agrotóxicos da cana (vizinho) } \\
\text { Trabalhar na chuva } \\
\text { Não poder trabalhar } \\
\text { Ficar parado } \\
\text { Fofocas, mentiras, humilhação, } \\
\text { frustração, estresse } \\
\text { Solidão } \\
\text { Isolamento } \\
\text { Preocupação }\end{array}$ \\
\hline Cidade & $\begin{array}{l}\text { Tem médico } \\
\text { Remédios } \\
\text { Tem postinho e hospital. } \\
\text { No que se refere à saúde, a cidade } \\
\text { somente é lembrada porque oferece } \\
\text { médico, remédio, SS. }\end{array}$ & $\begin{array}{l}\text { Falta alimentação } \\
\text { Comida envenenada } \\
\text { Falta apetite } \\
\text { Alimentos modificados } \\
\text { Químicos/hormônios } \\
\text { Risco de vida (no trabalho) } \\
\text { Trânsito } \\
\text { Dinheiro não dava } \\
\text { Falta de ânimo } \\
\text { Cansaço } \\
\text { Pressão } \\
\text { Mulher brigava com a gente } \\
\text { Violência } \\
\text { Andar desconfiado (roubo) } \\
\text { Alcoolismo } \\
\text { Falta solidariedade } \\
\text { Isolamento } \\
\text { As loucuras na TV (violência) }\end{array}$ \\
\hline $\begin{array}{l}\text { Não se referem } \\
\text { ao assentamento } \\
\text { ou à cidade }\end{array}$ & $\begin{array}{l}\text { Trabalha feliz } \\
\text { Não precisa ir ao médico } \\
\text { Não tem precisão de tomar remédio } \\
\text { Estar bem com o outro, com a vida } \\
\text { Viver em comunidade, conversar } \\
\text { Quebrar milho } \\
\text { Viver com fé em Deus } \\
\text { Saúde é o meio de viver }\end{array}$ & $\begin{array}{l}\text { Não se alimenta bem } \\
\text { Ficar pelos cantos } \\
\text { Correr para o posto (de Saúde) } \\
\text { Tomar químicos } \\
\text { Intoxicação } \\
\text { Azar na vida } \\
\text { Tristeza }\end{array}$ \\
\hline
\end{tabular}

Fonte: entrevistas realizadas em 2006 e 2007. 
trabalha, anda de carroça e à cavalo por aí, vai fazer todos os negócios. O utro que era muito gordo também, que veio de $M$ atão, é o [nome], que não conseguia abaixar para amarrar o sapato. $\mathrm{Hoje}$ vocêvêo peso do homem, agora ele consegue arrastar as vacas que ele tem, vai amarra, vem, anda, carpe, planta. Então se movimentando e com a cabeça despreocupada, a pessoa vai melhorando. 0 próprio [cita um outro assentado], que é muito pendurado. Elesofreu. Era muito magrinho, hojeé um peso de homem, mas vai nas atividades, tem um desempenho bom, porque se movimenta, conversa. Aí, então, pelas experiências e vendo essas pessoas, a gente vê que vai ajudando.

Para esses trabalhadores, o trabalho já não era apenas um espaço de realização da mais-valia e de dominação do capital, mas também espaço de resistência e de luta pelo controle das relações e condições de trabalho. Como dizem Dejours et al. ${ }^{18}$, o trabalho pode ser espaço de construção da saúde quando o modo de organização possibilita um campo de desafios e de liberdades para responder demandas complexase imprevistas, expressar emoções, desenvolver habilidades e reafirmar a autoestima. $N$ as situações detrabalho, conscientementeou não, seconstrói a saúde através da mobilização das potencialidades de adaptação próprias do ser humano, que tanto permitem enfrentar os desafios e gerar prazer quanto evitar o sofrimento.

Junto com a liberdade de movimentos do corpo, que já não ficava preso ao sedentarismo de determinados postos de trabalho, estava a liberdade para tomar decisões sobre quando e como trabalhar, de fazer a própria norma, do corpo e da mente: É importante um lugar desse porquea gente programa o dia da gente, por exemplo: vamos trabalhar? $\mathrm{N}$ ão, hoje eu vou pescar. $\mathrm{O}$ trabalho nas cidades, além de sujeito aos vários tipos de cargas, não gerava recursos suficientes para garantir a sobrevivência: $\mathrm{N}$ a cidade, não ganhava mal, ganhava bem. $M$ as, a gente via a criação das crianças, a violência da cidade. 0 dinheiro não dava para nada eaí viemos para cá, passamos dificuldade. Agora com o assentamento, já melhorou $100 \%$, a alimentação, a saúde.

No entanto, o trabalho no assentamento também era tido como fonte de adoecimento. Foram mencionadas cargas físicas, como ter que trabalhar sob a chuva, e químicas, relacionados à poeira, aos agrotóxicos e produtos maturadores queas usinas do entorno utilizavam nas plantações de cana que, por serem aplicados com aviões, atingiam e contaminavam o assentamento: No local quea gente está vivendo, não está lon- ge, estamos bem dentro dos químicos. Neste domingo mesmo, era sete horas da manhã, tinha um aviãozinho passando um produto de amadurecimento [na plantação de cana], é um produto químico, pega na alimentação da gente. $\mathrm{N}$ ós estamos numa ilha e, até que melhore, nem tanto a discussão, mas a formação das pessoas para o cuidado na alimentação, ter uma alimentação sadia, estamos longe ainda [de ter saúde]. 0 que piora a saúde é correr para o posto, tomar esses químicos.

Foram ainda mencionadas as cargas de natureza psíquica porque, apesar da liberdade que pode significar a vida e o trabalho no assentamento, os trabalhadores estavam sujeitos às condições climáticas que interferiam ou inviabilizavam a produção (excesso ou falta de chuva); sobretudo, eles estavam presos à falta de recursos financeiros e de condições mínimas para produzir, devido à lentidão na implantação do projeto de assentamento, e sofriam por isto.

0 trabalho tinha um sentido subjetivo importante para os assentados, quando se tratava de pensar a relação saúde-doença. Fisiológica e psicologicamente acostumados ao trabalho, eles sentiam falta do movimento que o trabalho ao ar livre impõe ao corpo, da aten ção e da concentração necessárias para trabalhar com instrumentos manuais e até da rotina que organizava o cotidiano. Assim, o trabalho era uma espécie deremédio ou terapêutica para resolver muitos problemas de saúde, especial mente aqueles relacionados ao funcionamento psíquico: Ficar sem fazer nada, parado, preocupado, vai prejudicar cada vez mais. Quando uma pessoa na cidadeseaposenta, não tem o que fazer, acaba se endurecendo, o salário que ganha acaba indo tudo em remédio, não é?

Observei muitas situações e ouvi inúmeros relatos sobre o fato deles se sentirem adoecidos pela ansi edade das várias incertezas e longas esperas, vividas no processo de implantação do projeto de assentamento: a demarcação dos lotes, a instalação da rede de energia, a construção das moradias, a abertura dos poços e a canalização da água, o acesso aos recursos do Programa Nacional de Agricultura Familiar (Pronaf), apenas para citar as mais importantes. A falta de condições objetivas para projetar a vida e o futuro gerava um sentimento de desamparo e de impotência, desgaste que afetava diferentemente a saúde de cada um e, sobretudo, afetava o processo organizativo do grupo, que perdia a unidade fazendo com que, cada vez mais, os trabalhadores investissem no cuidado individual em detrimento do coletivo: Antes do assentamento [no acampamento], era mais unido, um corria pelo 
outro. Depois que veio o assentamento, cada um pensa em si, esqueceu tudo isso, aquele projeto, aquela vivência para lutar junto. Quando a gente não tinha um arroz, um feijão, a gente saía, fazia arrecadação [de alimentos] e repartia. Hoje em dia, eu tenho meu alimento, ele tem o dele. 0 que mudou foi isto, mas ainda tem aqueles grupos que ol ham um do outro.

Além do trabalho, a qualidade das relações sociais e intersubjetivas também tinha um peso importante na relação saúde-doença. O Quadro 1 mostra que, no assentamento, a doença estava relacionada à existência de preocupação, isolamento, solidão, frustração, mentiras, fofocas. Deste ponto de vista, a saúde, por um lado, era produto da convivência em um lugar onde havia respeito, companheirismo eajuda mútua, as pessoas sentiam-se protegidas, em paz e alegres. As cidades eram representadas como lugares onde imperam a violência, a pressão e o isolamento, que levam as pessoas ao desânimo, à dependência de álcool e outras drogas, à violência urbana edoméstica, aosconflitos que se expressam, principalmente, no interior dasfamílias: Eu tenho um filho especial e na cidade ele trazia preocupação porque as pessoas não entendiam, ele bebia. No assentamento, não tem esteproblema porquetodos conhecem, sabem que ele não pode beber eaqui ele se desenvolve mais.

É a paz, paz éque dá saúdepara a gente. Q uando eu vou para cidade, para Ribeirão Preto principalmente, o trânsito, a genteanda desconfiado que pode roubar a gente. Eu me sinto doente. M eemociona, sai água dos meus olhos quando vejo a loucura na TV, aquelas famílias que poderiam estar aqui com a gente. Se o governo fizesse reforma agrária mesmo, muita gente poderia vir aqui com a gente, não teria nenhuma favela na cidade.

Foram estabelecidas articulações entre boa alimentação, convívio comunitário amistoso, bem-estar pessoal e o círculo vicioso que leva as pessoas a procurarem a assistência médica, a dependência dos químicos, o isolamento social: Porque muitas vezes você está na cidade e uma pessoa tem uma dor de cabeça ou na coluna, ou um "coiso" no estômago, acaba indo para o postinho e enche de remédio químico e a pessoa acaba se viciando, não é? D aí é complicado para saúde. M as, se você está bem, está de saúde, se alimentar bem, adequadamente, ter os horários certos, ter uma refeição bem balançada, aí que é saúde. $E$ estar com um convívio assim, estar em uma comunidade, conversar, brincar, não é? Nada de ser carrancoso. Q uando vocênão tem saúde mesmo é que fica pelos cantos.
Chama a atenção no Quadro 1 o fato de não existir nen huma referência à saúde na cidade, que somente foi lembrada ou porque nelas o modo de vida gera adoecimento ou porque é onde se encontram os serviços de saúde, os médicos e os remédios.

Os sentidos atribuídos por esses trabalhadores à saúde-doença somente podem ser adequadamente compreendidos considerando, por um lado, o modo como o M ST representa o assentamento ao problematizar a saúde: espaços saudáveis, arborizadose sob céu azul esol radioso, com frutas e flores, onde a convivência social é pacífica, as pessoas trabalham, passeiam e as crianças brincam felizes ${ }^{15}$, ou seja, um refúgio. Por outro lado, é importante considerar as trajetórias sociais dos trabalhadores, que são marcadas pelas experiências detrabalho precário einformal epela migração constanteem busca demelhores condições de trabal ho evida, portadores da "doença do desenraizamento"19 que encontraram no assentamento a possibilidade de enraizar, reconstruir a vida, trabalhar, recuperar laços familiares, se alimentar e morar com segurança, estudar. Trata-se de uma população vulnerável, portadora de um padrão de adoecimento diversificado e complexo, que combina as doenças crônico-degenerativas com as infecto-contagiosas e as de natureza psicológicas, ese explica tanto pelas trajetórias de trabalho e de vida quanto pelas necessidades ainda vivenciadas no assentamento.

\section{A saúde em prática}

Os trabalhadores recorriam a um conjunto de práticas para cuidar da saúde queincluíam desde a busca de atenção nos serviços localizados no entorno até as práticas religiosas, passando pelo uso de plantas medicinais e pelas propostas que valorizam as atividades socioculturais, o lazer e o esporte. Para discutir a relação dessas práticas com o sentido atribuído à saúde-doença, é importante considerar como os trabalhadores se relacionavam com o sistema de saúde local.

0 assentamento localiza-se em uma região ondeexisteuma rede deserviços públicos de saúde estruturada. Porém, no pequeno município que o abriga - típica cidade dormitório de bóias-frias - a infraestrutura de atenção básica é precária. A população rural não tem inserção formal no sistema de saúde municipal e, segundo os trabaIhadores, o PSF rural ainda não foi implantado por falta de recursos financeiros. Os assentados recebem atenção emergencial eos casos demédia 
e alta complexidade são encaminhados para outros municípios. A relação com os serviços de saúde do entorno foi sendo construída eatéhoje semantém por força de acordos informais ecompromissos políticos firmados com os poderes públicos locais, dos quais dependem o tipo e a qualidade dos atendimentos. O corre que, para as pequenas prefeituras do entorno, um assentamento com oitenta famílias significa muita coisa: desde a potencialidade de imprimir um dinamismo maior ao comércio local, atéo peso deter que arcar com as demandas por serviços e bens de consumo coletivo, especialmente saúde e educação, passando pela ampliação do número de eleitores.

No início, a relação do poder local com os assentados foi de estranhamento porque, afinal, tratava-se de sem-terras que, aos ol hos da população em geral, são invasores de propriedades, pobres e violentos. Porém, a aproximação foi revelando um universo de possibilidades de relacionamento até chegar ao ponto de tanto haver disputa quanto "jogo de empurra". A falta de unidade na ação dos coordenadores de saúde do assentamento, cuja responsabilidade é fazer a mediação entre os assentados e o SUS, os tornava vítimas do assédio dos políticos do entorno. Apesar dos esforços e das boas intenções, a atenção à saúde dos assentados ficava à mercê do jogo de interesses, interno e externo, submetida às trocas de favores e às atitudes discriminatórias que resultavam no desrespeito aos princípios e normas do SUS, especialmente a regionalização, na centralização de informações e recursos, na reprodução do assistencialismo e do paternalismo ena oferta deuma atenção à saúde queé, tecnicamente, precária einsuficiente. Para resolver os problemas, enquanto alguns coordenadores propunham negociação, outros propunham que se ignorassem os direitos e que as ações pudessem garantir a independência do sistema (por exemplo, criar um sistema próprio para o transporte de enfermos e um PSF rural exclusivo para 0 assentamento). A demanda não era organizada e, além do pronto atendimento, consultas de rotina tinham tempo de espera superior a três ou quatro meses porque, segundo os entrevistados, a prioridadeera aten der os moradores da cidade. A falta de profissionais nos serviços tornava mais fácil obter vacinas e remédios do que consultas, 0 que incentivava a automedicação.

A realidade deste assentamento não é particular. Leite et al. ${ }^{13}$ afirmaram que a criação de assentamentos no Brasil tem sido feita sob forte pressão social e sem o devido planejamento no que se refere à oferta de serviços essenciais, especialmente na área da saúde. Isto, além de comprometer a saúde dos assentados, torna ainda mais precária a atenção à saúde nos municípios do entorno.

Apesar das dificuldades de acesso encontradas e das orientações preventivistas do MST, a procura dos trabalhadores assentados por consultas e remédios era grande, explicada pela força da concepção individualista, curativa e medicalizante que reforça o hábito da busca de assistência no serviço de saúde, mesmo em condições muito adversas: Procuram o médico porque é mais rápido. Tem médico que quando você entra [ no consultório], elejá está com a receita na mão. Aspessoas fogem muito da linha que o MST quer: uma saúdealternativa, fugir do laboratório químico. $\mathrm{Na}$ realidade, as pessoas procuram o mais fácil, vai ao postinho de saúde e o médico receita o dicrofenato e a dipirona e acha queéa solução. Se a gente trabaIhar em cima da cultura, do resgate das plantas medicinais, [o princípio ativo] éo mesmo que está naquele remédio. 0 que muda na saúde de quem está no assentamento? M elhora muito, a pessoa mexe com a terra. Só que o nosso povo é muito dependente, quer o mais fácil, mais rápido.

Parece haver uma contradição entre esta afirmação e o sentido atribuído pelos trabal hadores à saúde-doença, centrado na alimentação regular e de boa qualidade, na liberdade de organizar 0 trabal ho de acordo com as necessidades fisiológicas e psíquicas e na restauração das formas de apoio social. A meu ver, apesar dos esforços do MST em discutir a saúde como direito ede pensála para além da assistência médica, ainda predominavam as práticas de saúde individualistas, biologicistas e curativas por vários motivos. Primeiramente, porque há uma necessidade concreta de lidar com as doenças já instaladas, que requerem atenção especializada, trazidas como parte de uma história de trabal ho e de vida que o sistema de saúde não tem logrado cuidar adequadamente, nem mesmo depois que essas pessoas se fixaram no assentamento. Em segundo lugar, a procura pelo serviço de saúde pode estar sendo uma forma de lidar com o isolamento ea solidão, responsáveis pela ansiedade e pela depressão. A necessidade de apoio social, dimensão subjetiva considerada importante no processo saúde-doença, pode não estar sendo adequadamente suprida no âmbito do coletivo, apesar do ideal de cooperação e solidariedade que o permeia.

Durantea pesquisa, ouvi relatos de experiências de cura através da fitoterapia e de orações, práticas de saúde aparentemente muito utiliza- 
das, embora não tenha sido possível avaliar pre cisamente em que medida elas fossem complementares ou substitutivas da busca de assistência nos serviços de saúde. Ambas fazem parte das heranças culturais trazidas para 0 assentamento, que estão sendo mantidas ou resgatadas como estratégias de cuidado com saúde na medida em que contribuem, de um modo ou de outro, para resolver os problemas.

No que se refere à fitoterapia, Godoy et al. ${ }^{9}$ mostraram que esta prática existe em $70 \%$ das áreas de assentamentos e é utilizada por metade das famílias que neles residem. No assentamento investigado, entre os motivos da utilização da fitoterapia estavam a precariedade da atenção oferecida pela redede serviços públicos, a ausência de recursos para buscar assistência no âmbito privado, a existência de um saber popular e tradicional acumulado, o incentivo à utilização dado pelos profissionais dos serviços de saúde, a relação estabelecida entre saúdeeum modo conservacionista e naturalista de levar a vida. Além de ser uma tecnologia de cuidado acessível porque resgata saberes e práticas populares, a fitoterapia permitia discutir o problema da biopirataria que ameaça a biodiversidade brasileira, do monopólio da indústria farmacêutica e ainda possibilitava gerar renda através da comercialização de mudas, plantas e remédios. No entanto, o cultivo de plantas medicinais ainda era restrito a al guns lotes, não estava estruturado nem como prática de saúde generalizada enem como prática econômica. 0 projeto de assentamento prevê a construção de um viveiro de plantas medicinais para uso comunitário; no entanto, as tentativas de organizá-lo esbarravam na falta de materiais e insumos, especialmente água, recursos ainda inexistentes devido à morosidade na implantação do projeto de assentamento.

A intenção deinvestir em fitoterapia era também uma forma de garantir a independência de um sistema de saúde ineficiente. A pergunta sobre se ainda usariam plantas medicinais para cuidar da saúde se tivessem disponibilidade de médicos e remédios sempre teve resposta afirmativa eas justificativas remetiam às experiências de cura ou de erro médico vividas e ao conhecimento acumulado sobre o uso de plantas medicinais ou sobre os efeitos iatrogênicos da medicinatradicional.

A ausência derecursos ea presença das doenças nos familiares e de pragas nas lavouras e currais faziam os trabalhadores apelarem à fé, tornando a religião tanto prática de cuidado à saúde humana quanto das plantas e animais e for- ma de aliviar a ansiedade gerada pela impossibilidade de, sozinhos, solucionarem os problemas. Porém, não se tratava de ter a religião como espaço de sociabilidade e de construção de formas de apoio social ${ }^{20}$, mas como ferramenta para exorcizar o "demônio da doença".

A diversidade de práticas de saúde estava relacionada à própria diversidade sociocultural dos trabalhadores. Elas não eram excludentes, mas eram utilizadas na medida da disponibilidade e do tipo de problema de saúde a ser resolvido. E havia ainda os que defendiam o lazer eas atividades socioculturais, como estratégias coletivas de promoção da saúde. 0 que chamavam de prevenção, na verdade, eram ações de promoção, enfocadas sob diferentes aspectos: a luta política contra o monopólio da indústria química que produz conhecimento para beneficiar determinados setores da sociedade, a formação dos trabaIhadores para produzir, manipular eutilizar plantas medicinais, a articulação entre setores de saúde, educação e cultura, a criação de espaços comunitários socioeducativos onde a saúde articula-se com a cultura popular a partir das atividades esportivas e delazer, da convivência festiva, da arte, da troca de saberes no sentido de combater 0 isolamento e a solidão, motivos da doença.

No entanto, nenhuma dessas propostas epráticas havia, de fato, se concretizado. A prioridade dos trabal hadores ainda era a luta para concluir a implantação do projeto de assentamento e para viabilizar a produção. Lutar pelo acesso aos recursos do Pronaf tem sido mais importante do que lutar pelo acesso aos serviços de saúde, já que produção envolve a segurança alimentar, considerada condição essencial da saúde.

\section{Consideraçõesfinais}

No assentamento analisado, apesar de os trabaIhadores terem encontrado melhores condições para trabalhar, se alimentar e viver com segurança, a saúde, como direito social, era ainda um ideal enão havia práticas coletivas queavançassem nesta direção. Entre sentidos idealizados e práticas possíveis, o cuidado com a saúde vinha sendo feito a partir de uma rede de atenção improvisada, voltada para o emergencial emal amparada por práticas complementares que, desenvolvidas no âmbito individual, nem sempre conseguiam satisfazer as crônicas necessidades. As tentativas para solucionar os problemas e concretizar osideais de saúde preconizados pelo M ST esbarravam nas dificuldades relacionadas à falta de condições ade- 
quadas para produzir ecomercializar (crédito, tecnologia e assistência técnica) e de infraestrutura para viabilizar a vida social (moradia, energia elé trica, água, estradas, transporte, educação, assistência à saúde) e à dificuldade para superar a cultura da submissão e da dependência, que individualiza e naturaliza os agravos à saúde.

O processo deimplantação deste assentamento é revelador do modo fragmentado e desarticulado com que as políticas públicas envolvidas na reforma agrária têm sido implementadas pelo Estado. Embora minimizem a pobreza que afeta esses trabalhadores, elas não têm contribuído para diminuir as desigualdades sociais e para fortalecer a autonomia política dos sujeitos. Elas apenas têm amortizado as pressões sociais dos demandantes de terra e criado uma ilusão de autonomia por que valorizam e estimulam a livre iniciativa e delegam aos sujeitos o cuidado sobresi mesmos, o que só reforça a tendência de diminuição da responsabilidade do Estado na solução dos problemas sociais. A idéia de autonomia queestá presentena concretização do projeto de desenvolvimento econômico e social que tem sido defendido há décadas pelos movimentos sociais do campo é outra: trata-se da participação ativa e organizada de sujei tos coletivos na elaboração e implementação de políticas públicas intersetoriais voltadas para a melhoria das condições de trabalho e vida.

\section{Referências}

1. Scopinho RA. Vigiando a vigilância: saúde e segurança no trabalho em tempos de qualidade total. São Paulo: Annablume-Fapesp; 2003.

2. Silva MAM. A morte ronda os canaviais. Revista da ABRA 2006; 33(2):111-141.

3. Novaes JR. Campeões de produtividade: dores e febres nos canaviais paulistas. Estudos Avançados 2007; 21(59):167-177.

4. Martins JS, organizador. Travessia. A vivência da reforma agrária nos assentamentos. Porto Alegre: Ed. UFRGS; 2003.

5. Scopinho RA. Sobre cooperação e cooperativismo em assentamentos rurais. Revista Psicologia \& Sociedade 2007; 19(Número Especial):84-94.

6. Silva LAM, organizadora. Condições de vida das camadas populares. Rio de Janeiro: Zahar; 1982.

7. Telles VS. A experiência da insegurança: trabalho e família nas classes trabalhadoras urbanas em São Paulo. Tempo soc. 1992; 4 (1-2):53-93.

8. Bourdieu P. Compreender. In: Bourdieu P. A miséria do mundo. 4a ed. Petrópolis: Vozes; 1997. p. 693-713.

9. Godoy $A$, M orás $M$, Aucélio $P Q$, organizadores. A saúde dos trabalhadores rurais de assentamentos e acampamentos de reforma agrária. Brasília: UNBCeam-N esp/M ST -Setor N acional de Saúde; 2000.

10. Schmidt BV. Os assentamentos de reforma agrária no Brasil. Brasília: Ed. UnB; 1998

11. Pérez MAG. 0 trabalho "doente" entre assentados rurais [dissertação]. Campinas (SP): Unicamp; 2001.

12. Sparovek G. A qualidade dos assentamentos de reforma agrária brasileira. São Paulo: Páginas \& Letras Editora e Gráfica; 2003.

13. Leite $S$, Heredia B, M edeiros L, Palmeira M, Cintrão R. Impacto dos assentamentos. Um estudo sobre o meio rural brasileiro. São Paulo: Ed. Unesp; 2004.
14. Soares CO. Institucionalização e relações sociais na atenção à saúde em um assentamento rural: 0 caso do H orto Vergel [dissertação]. Campinas (SP): Unicamp; 2005.

15. Movimento dos Trabalhadores Rurais Sem Terra (MST). Construindo o conceito de saúde do MST. Brasília: M ST; 2000. p.12.

16. Movimento dos Trabalhadores Rurais Sem Terra. 0 MST e o meio ambiente. A reforma agrária é uma maneira de cuidar do meio ambiente. São Paulo: MST; $\mathrm{s} / \mathrm{d}$.

17. M ovimento dos Trabalhadores Rurais Sem Terra. Programa Terra e Saúde. Das plantas construindo uma nova saúde. São Paulo: M ST; 1999.

18. Dejours $C$, Abdouucheli $E$, Jayet $C$. Psicodinâmica do trabalho: contribuições da escola dejouriana à análise da relação prazer sofrimento e trabalho. São Paulo: Atlas; 1994.

19. Weil S. Desenraizamento. In: Bosi E, organizadora. Simone Weil: a condição operária e outros estudos sobre a opressão. 2a ed. Rio de Janeiro: Paz e Terra; 1996.

20. Valla VV. Educação e saúde: discutindo as formas alternativas de lidar com a saúde. In: Goldenberg P, M arsiglia RM G, Gomes MHA, organizadores. 0 clássico e o novo: tendências, objetos e abordagens em ciências sociais e saúde. Rio de Janeiro: Fiocruz; 2003. p. 363-378.

Artigo apresentado em 27/09/2007

Aprovado em 14/12/2007 